\title{
DCs gather crumbs to feed memory
}

Acute viral infections are rapidly cleared by the host immune system, but there is evidence that depots of viral antigen can persist after the resolution of infection and sustain memory T cells. Previous studies suggested that these reservoirs are located in lymph nodes draining the site of infection; Kim et al. now show that residual viral antigens persist in the post-infective tissue itself and are transported to the draining lymph nodes by migratory dendritic cells (DCs).

In a mouse model of acute influenza virus infection (in which infectious virus is typically undetectable by $8-10$ days post-infection), transgenic virus-specific $\mathrm{T}$ cells were found to proliferate in lymph nodes draining the lung for at least 30 days after infection. Notably, mRNA encoding influenza virus gene products could not be detected

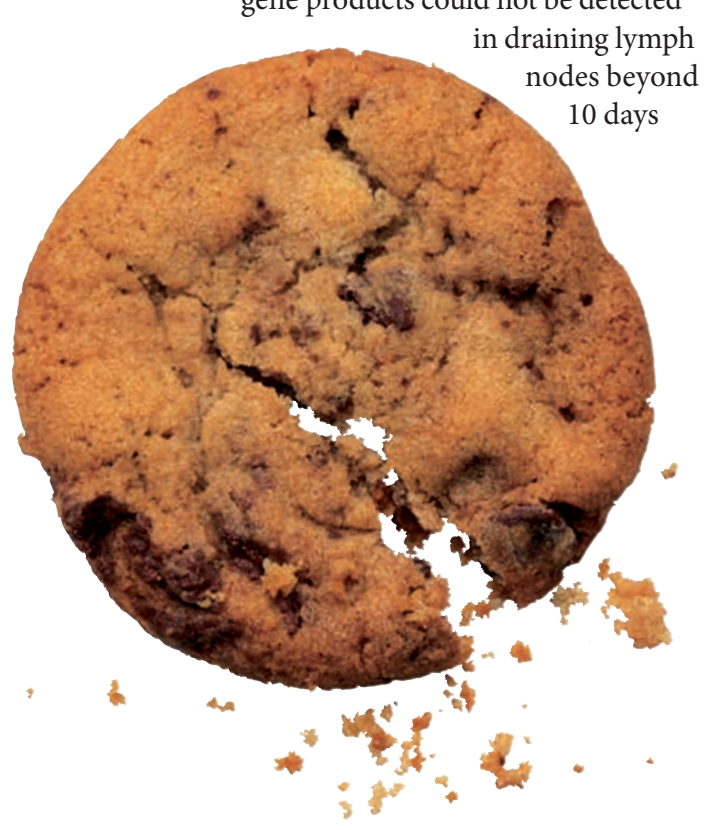

post-infection, but viral mRNA was still present in lung tissue at 30 days following infection. Furthermore, viral nucleocapsid protein could be detected in the lung for up to 30 days post-infection; this was mainly associated with $\mathrm{CD}^{-} 5^{-}$cells within small residual inflammatory loci.

These findings suggested that, post-infection, proliferation of virusspecific $\mathrm{T}$ cells in the draining lymph nodes requires transport of viral antigen from the lung depots. Predicting that DCs might be responsible for this antigen delivery, the authors explored the role of different antigenpresenting cells (APCs) in their infection model. When various APC subsets were harvested from draining lymph nodes at day 20 post-infection, only two distinct populations $\left(\mathrm{CD}_{103}{ }^{+}\right.$and $\left.\mathrm{CD} 11 \mathrm{~b}^{\mathrm{hi}} \mathrm{DCs}\right)$ could stimulate virus-specific naive $\mathrm{T}$ cells to proliferate ex vivo. Experiments with intranasally delivered fluorescently labelled antigen showed that the $\mathrm{CD}_{103^{+}}$and CD $11 \mathrm{~b}^{\text {hi }}$ DCs could take up antigen in the post-infected lung and then transport this to the draining lymph nodes. Furthermore, the selective depletion of $\mathrm{CD}_{103}{ }^{+}$and $\mathrm{CD} 11 \mathrm{~b}^{\mathrm{hi}}$ lung DCs at day 20 post-infection abolished the proliferation of adoptively transferred virus-specific T cells in the draining lymph nodes.

Next, investigating the antigen depots in the lung, the authors found that these were radioresistant but dependent on lymphotoxin- $\beta$ (LT $\beta$ )-mediated signalling. Blockade of LT $\beta$-mediated signalling markedly reduced the number of follicular DCs
(FDCs) in the post-infected lung, prompting the authors to speculate that FDCs within inducible lymphoid structures function as antigen reservoirs in the post-infected lung. Finally, the authors explored the effects of DC-mediated transport of residual viral antigens on the endogenous memory $\mathrm{T}$ cell pool. At days 30 and 70 post-infection, increased numbers of virus-specific memory $\mathrm{CD}^{+}$and $\mathrm{CD} 8^{+} \mathrm{T}$ cells were found in lung-draining lymph nodes, but not in lymph nodes draining other tissues. Notably, selective depletion of $\mathrm{CD}_{103^{+}}$and $\mathrm{CD} 11 \mathrm{~b}^{\text {hi }}$ migratory lung DCs at day 30 post-infection markedly decreased the number of memory $\mathrm{T}$ cells found in the draining lymph nodes; this defect could be corrected by adoptively transferring lung DCs, but not alveolar macrophages, indicating the importance of DC delivery of residual antigen for a long-term memory response.

These data propose a mechanism for the preferential accumulation of memory T cells in lymph nodes draining sites of infection. Furthermore, they suggest that vaccine strategies involving longlasting antigen depots at the site of infection should be the most effective for sustaining protective memory $\mathrm{T}$ cell responses.

Yvonne Bordon

ORIGINAL RESEARCH PAPER Kim, T. S. et al. Antigen persistence and the control of local T cell memory by migrant respiratory dendritic cells after acute virus infection. J. Exp. Med. 31 May 2010 (doi:10.1084/jem.20092017) 